\title{
CORRESPONDENCE
}

\section{FLYING BOATS}

The Secretary,

The Royal Aeronautical Society,

7, Albemarle Street, London, W. I.

Dear Sir,-I was unfortunately prevented from being present on the occasion of Major Rennie's paper on the long-range flying boat, or I should have associated myself then with Mr. Pierson's disagreement with Major Rennie's Fig. I giving range against total weight.

I now note in the lecturer's reply in the Journal of April, 1928, that he stands his ground on this point, and in view of its fundamental importance to all interested in long-range work, whether it be of flying boats or of land planes; I am moved to record my initial views.

In Fig. I, page 265, Major Rennie takes the same mileage per gallon of fuel expended whether the machine be loaded to $20,000 \mathrm{lbs}$. or $40,000 \mathrm{lbs}$, i.e., doubling the total weight also doubles the ton-miles per gallon. As I read his reply to the discussion, Major Rennie justifies this singular position by stating that "calculations and actual consumption tests show that for a given aireraft the air-miles per gallon at cruising specd varies nearly linearly with the weight of the aircraft." With this broad statement I am in general agreement, but in my opinion the variation is insufficiently nearly linear to justify an approximation when small differences in range are under consideration, nor can it be used with accuracy over wide variations in weight.

It will thus be seen that Major Rennie's further statement (page 294) that " it is quite correct when estimating the range to use the value of the air-miles per gallon corresponding to the weight of the aircraft with half fuel," has only a very limited application.

From the data I assume that the range of the three-engined flying boat with Rolls Royce "Condor" engines under consideration in Fig. I when loaded to 29,000 lbs. with 1,500 gallons of fuel is 1,730 miles. The weight of the aircraft with tanks when all this fuel is consumed appears to be about 19,000 lbs., and the weight of the aircraft with half fuel is, therefore, 24,000 lbs. Accepting the lecturer's figures for range we obtain a consumption at this weight of $\mathrm{I}_{\text {. }} 3$ miles per gallon.

Now on Major Rennie's own admission, when considering the range loaded to 39,000 lbs., say, we must take the consumption at half-load, i.e., 29,000 lbs. But by showing a straight line for range against weight he clearly retains 24,000 lbs., his original half-loaded weight, as his criterion of consumption, ans thus departs radically from the actual conditions.

In order to exhibit the differences involved a few figures are appended which have been calculated on the somewhat meagre data available, but which I believe to be not very far from the truth.

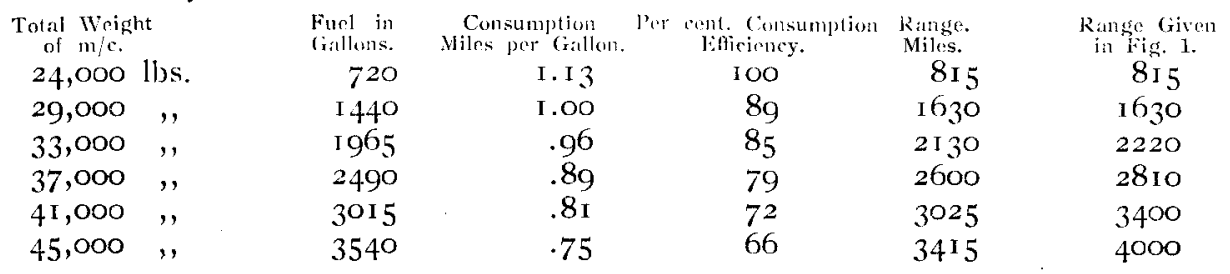


At the highest weight taken the linear graph over-estimates the range by nearly 600 miles or 17 per cent., which in any case must be a serious matter. As the weight further increases the error becomes aggravated, as can be seen from the consumption columns.

Another way of stating the problem is that if consumption varies linearly with weight, then the range-weight graph, which is the first integral of the consumption-weight graph, must clearly be a parabola; but this statement does not indicate the quantitative differences involved.

Had this question not had a very practical application I should have hesitated to claim so much space in your pages, but at least one of the trans-Atlantic expeditions of 1927 based all its calculations on a linear range-weight graph, as in Fig. I, and only at the eleventh hour realised the jeopardy of such an approximation.

I feel it cannot be too highly emphasised to those about to make long-distance flights that the consumption in the early hours of the flight (i.e., when the machine is most heavily loaded) is likely to be much more heavy than rough computation may indicate. Detailed calculations do, however, give closely accurate figures and to ignore them is to court disaster.-Yours faithfully,

O. E. Simmonis. 